\title{
EMPREENDER OU NÃO EMPREENDER? FATORES CONDICIONANTES NA FORMAÇÃO DA INTENÇÃO EMPREENDEDORA
}

Déborah Luiza Marcon ${ }^{1}$

Amelia Silveira $^{2}$

Jucelia Appio Frizon ${ }^{1}$

\footnotetext{
${ }^{1}$ Universidade Estadual do Oeste do Paraná

${ }^{2}$ Universidade Federal de Santa Catarina
} 


\section{EMPREENDER OU NÃO EMPREENDER? FATORES CONDICIONANTES NA FORMAÇÃO DA INTENÇÃO EMPREENDEDORA}

Resumo: Muitos são os fatores que determinam a decisão dos indivíduos de iniciar um empreendimento. Neste sentido, o artigo busca analisar a influência de fatores sociodemográficos e comportamentais sobre dois grupos de indivíduos: os que possuem intenção de empreender e os que não possuem intenção de empreender. O estudo caracterizase como quantitativo e descritivo, adotando questionário, e método de regressão logística. A amostra considerou 371 estudantes universitários de cursos de graduação em Administração, de onze instituições de ensino superior, localizadas na região sudoeste do Paraná. Este tem sido o delineamento da maioria das pesquisas realizadas, nesta temática de interesse (RUEDA, MORIANO, LIÑÁN (2015). Os resultados indicam que os fatores comportamentais são os que possuem maior poder de explicação nas intenções empreendedoras. Em seguida, destacam-se os fatores referentes ao acesso à educação para o empreendedorismo e a atividade profissional atual. Gênero, familiar empreendedor e renda não se mostraram significativos no modelo adotado.

Palavras-chaves: Intenção empreendedora. Fatores sociodemográficos. Fatores comportamentais. Acesso à educação empreendedora.

\section{Introdução}

Ao empreendedorismo é atribuído um papel relevante para a promoção do desenvolvimento econômico de regiões, em virtude de seus efeitos de geração e expansão de negócios, empregos, distribuição de renda e oportunidades de ascensão social (LIÑÁN; RODRIGUEZ-COHARD; RUEDA-CANTUCHE, 2011; DOS SANTOS; SÁ BARRETO; GUZMAN, 2017). Nesse sentido, é de importância identificar e apoiar indivíduos com intenções empresariais (SHANE, 2009). No contexto educativo, mais especificamente, Lima et al. (2015b) argumentam que a educação para o empreendedorismo busca novas formas de aperfeiçoamento. Entende-se que, no Brasil, deverá ter futuro promissor no ensino superior, bem como no surgimento, aperfeiçoamento e crescimento de empresas, instituições, negócios e tecnologias. Apesar da unanimidade a respeito da importância de desenvolver o comportamento empreendedor, por meio da educação empreendedora, ainda não há homogeneidade nas discussões acadêmicas a respeito do que determina a eficiência dessa educação (KRÜGER; BÜRGER; MINELLO, 2019). Recentes análises foram conduzidas e comprovaram a existência de uma relação positiva entre a educação empreendedora e a intenção empreendedora (BAE et al., 2014; KRÜGER; BÜRGER; MINELLO, 2019).

Nesse sentido, este artigo tem por objetivo explicar a influência de fatores sociodemográficos e comportamentais, incluindo o acesso à educação empreendedora, sobre dois grupos de estudantes universitários: os que possuem intenção de empreender e os que não possuem intenção de empreender. 
Para isso, inicialmente, é apresentada uma contextualização da intenção empreendedora, os diferentes modelos que a analisam e os principais fatores influenciadores que a bibliografia reporta. Na sequência consta a metodologia de pesquisa e, ao fim, seus resultados e conclusão.

\section{Intenção empreendedora (IE)}

O campo de pesquisa sobre empreendedorismo tornou-se alvo de muita atenção ao longo das últimas cinco décadas, sendo fundamental na construção de sua infraestrutura conceitual (LANDSTRÖM; HARIRCHI; ASTRÖM, 2012). O tema tem sido amplamente discutido no contexto econômico-social, sendo objeto de estudo de diversos pesquisadores, visando entender sua importância no processo de desenvolvimento econômico-regional, de maneira mais equilibrada e sustentável (VIANA et al., 2016).

A pesquisa sobre empreendedorismo, por sua própria natureza, é um campo multi e interdisciplinar de investigação e, além disso, é explicitamente aberto e exige novas perspectivas, mais pesquisas e práticas que contribuam para sua distinção e seu desenvolvimento (FRANCO; GOUVÊA, 2008).

A temática tem instigado o pensamento sobre as atitudes e intenções empreendedoras e o modo como estas se relacionam com contextos diversos, podendo se tornar um dos caminhos a serem trilhados na busca por soluções em produtividade, competitividade, inovação e desenvolvimento local (JULIEN, 2010). Por sua vez, o processo de intenções empreendedoras pode começar com as necessidades, valores, desejos, hábitos e crenças pessoais do indivíduo (BIRD, 1988). Para Krueger, Reilly e Carsrud (2000), os modelos de intenção são superiores aos modelos de abordagem tradicional, uma vez que os empreendedores também são moldados por fatores motivacionais, o ambiente social e suas percepções de habilidades pessoais. Portanto, é relevante mencionar os fatores sociodemográficos e comportamentais que então envolvidos no processo de empreender, para entender o modo pelo qual as intenções empreendedoras são adquiridas e potencializadas (TORRES, el al., 2017). Além disso, os estudos e discussões relacionados à formação da IE têm crescido constantemente, ganhando cada vez mais relevância (SILVEIRA et al., 2017).

\section{Fatores sociodemográficos}

Muitos são os fatores que determinam a decisão dos indivíduos de iniciar um empreendimento (RUEDA, MORIANO, LIÑÁN, 2015). No entanto, estudos evidenciaram que a IE é determinada por um conjunto diversificado de questões que podem ser agrupadas em dois aspectos: um relacionado a fatores individuais e outro relacionado a aspectos ambientais, entre os quais estão as características socioeconômicas e sociodemográficas (LIÑÁN, 2008). De fato, a segunda questão importante na análise da IE são os fatores sociodemográficos, conforme observado por Liñán e Fayolle (2015) em uma extensa revisão de literatura. Dentre outros se pode destacar Tarapuez, García e Castellano (2018), que estudaram a relação de treze aspectos socioedemográficos com a intenção empreendedora de 297 estudantes universitários da Colômbia, por meio de Análise de Correspondência Múltipla e Regressão Logística. Os autores constatarams que os dois aspectos que mais influenciam a intenção empresarial dos universitários são o "tipo de universidade" e "ter um amigo de negócios". Por outro lado, várias 
associações foram observadas entre as modalidades das variáveis qualitativas, que pertencem aos estratos socioeconômicos mais altos.

Ainda considerando os fatores sociodemográficos, outros pesquisadores também evidenciaram o fator família, visto que pais empreendedores motivam os jovens a se envolverem nesses tipos de atividades (MEDINA; BOLIVAR; LEMES, 2014). A partir disso, tem sido sugerido que quanto maiores as possibilidades de uma pessoa observar e interagir com empreendedores bem-sucedidos, maior a intenção de criar uma empresa (SÁNCHEZ, 2009). Daí a importância de estar em um ambiente em que haja referências empreendedoras, pois estas se tornam uma inspiração para que outras pessoas possam iniciar seu próprio negócio e, assim, gerar aprendizado social (TORRES et al., 2017).

Os estudos de Olmos e Castilho (2015), entre outros, destacam-se como os que constataram forte influência dos pais ou mentores na autoconfiança e na IE. E forte influência da experiência empreendedora da família na criação de negócios, estudantes e empresários. De forma geral, os resultados indicaram uma relação altamente significativa entre a intenção empresarial e a presença de um pai ou outro parente que possua uma empresa familiar (com um nível decrescente de significância nessa relação para a mãe ou irmãos).

Paiva et al. (2019) analisaram a influência de construtos comportamentais sustentáveis e inovadores no empreendedorismo e a influência da família e do gênero na intenção empreendedora, em uma amostra de 429 estudantes de uma universidade pública, a partir da analise da regressão logística, e os resultados, junto aos alunos do Curso de Adminstração, evidenciaram que a influencia da família se mostrou signficativa, com o valor de coeficiente B de 1.408 e um odds ratio de 4.089.

Considerando-se o fator sociodemográfico família, apresenta-se a primeira hipótese de pesquisa:

\section{H1: O fator sociodemográfico família distingue os estudantes com intenção empreendedora.}

Outro fator sociodemográfico presente em inúmeras pesquisas de intenção empreendedora é o fator gênero. Na pesquisa de Soria-Barreto et al. (2017), realizada com 351 estudantes de administração de empresas no Chile e na Colômbia, baseando-se no modelo de Ajzen (1991), os resultados mostraram que o gênero e a experiência empreendedora anterior (experiência de trabalho) agem como moderadores para as variáveis explicativas da intenção empreendedora. Além disso, que o gênero é um moderador do comportamento de controle percebido com $95 \%$ de confiança, o que explica que se um homem percebe o controle comportamental, este é potencializado, afetando positivamente a relação com a intenção empreendedora. Em outro sentido, Tarapuez, García e Castellano (2018) estudaram a relação de treze aspectos socioedemográficos com a intenção empreendedora de 297 estudantes universitários da Colômbia. Os resultados mostraram que nenhuma influência de gênero foi vista na intenção de negócios dos estudantes universitários.

Levando em conta o fator gênero, apresenta-se a segunda hipótese de pesquisa:

H2: O fator sociodemográfico Gênero distingue os indivíduos com intenção empreendedora.

Entre os diversos fatores sociodemográficos que podem influenciar positivamente o desenvolvimento da IE, também se pode considerar a educação para o empreendedorismo (EE), pois há evidências de que as pessoas inscritas nos programas de EE têm níveis 
significativamente mais altos de IE (FAYOLLE; LIÑÁN, 2014). Nesse sentido, a educação para o empreendedorismo será o próximo fator evidenciado como influenciador da IE.

\subsection{Educação para o empreendedorismo}

O processo de educação para o empreendedorismo (EE) envolve o aprendizado de conhecimentos, habilidades, atitudes e qualidades de várias disciplinas, bem distinto do ensino de uma teoria (LOPES, 2010; NECK et al., 2014). Esse processo prepara os estudantes com conhecimentos e competências para defrontarem os desafios de criação, condução e expansão de negócios (SILVA; PENA, 2017). Segundo Oliveira (2016), a construção e evolução da rede temática da $\mathrm{EE}$, como um campo científico, atravessou vários estágios de desenvolvimento. Nesse mesmo sentido, o autor também afirma que o desafio que se impõe consiste em reformular os programas, de forma que as competências empreendedoras ocupem destaque nas matrizes curriculares. Para reforçar o futuro da educação para o empreendedorismo, são necessários fortes fundamentos intelectuais e conceituais, provenientes das áreas do empreendedorismo e da educação, e também se é preciso refletir profundamente sobre as práticas de pesquisadores e educadores, tomando uma postura mais crítica (FAYOLLE, 2013).

O estudo de Lima et al. (2015a) examinou as formas de se melhorar a EE, utilizando a amostra do Guesss, composta por 12.604 estudantes brasileiros, constatando que tais estudantes têm demanda mais alta por EE do que se vê. Apesar de haver elevada demanda desses estudantes por EE, a percepção de capacidade para empreender (auto eficácia) se mostrou indiferente a ela, ou seja, a EE não prediz a IE, revelando que a EE talvez não esteja atingindo seu objetivo de promover o empreendedorismo. Bignotti e Le Roux (2016) investigaram o efeito individual e combinado da educação empreendedora e características empreendedoras sobre as intenções empreendedoras de 827 estudantes matriculados no programa Mini Enterprise da Junior Achievement South Africa (JASA). Revelaram que a educação empreendedora e as características empreendedoras por si só não influenciam positivamente as intenções empreendedoras. No entanto, uma vez introduzidos os efeitos da interação, a educação para o empreendedorismo moderou a influência da necessidade de realização e apoio familiar às intenções empreendedoras numa direção positiva. $O$ objetivo da pesquisa de Ferreira, Fernandes e Ratten (2016) foi analisar, a partir de uma teoria da perspectiva de comportamento planejado, o papel da educação do empreendedorismo e da intenção empreendedora. A pesquisa foi aplicada a estudantes universitários brasileiros, e seus resultados mostraram que a idade, a ocupação do pai e a propensão ao risco influenciam a intenção do indivíduo em se envolver em comportamento empreendedor.

Do ponto de vista teórico, diversos estudos usaram frequentemente modelos baseados em intenções para avaliar o impacto das intervenções de EE. Buscando entender a influência da educação para o empreendedorismo na intenção empreendedora, tem-se a seguinte hipótese de pesquisa:

H3: $O$ fato de ter tido acesso a programas de educação para o empreendedorismo dentro da universidade distingue os estudantes com intenção empreendedora.

Além dos fatores sociodemográficos e a educação para o empreendedorismo, os fatores sociológicos, psicológicos e motivacionais, aqui chamados de fatores comportamentais, também desempenham um papel importante na formação das intenções de um indivíduo (OLMOS; CASTILHOS, 2015). 


\section{Fatores comportamentais}

Ajzen (2011) indica que, segundo a Teoria do Comportamento Planejado (TCP), a ação humana é influenciada por três diferentes fatores: uma avaliação positiva ou negativa de um comportamento (atitudes), a pressão social para realizar ou não o comportamento (normas subjetivas) e a percepção sobre a capacidade de se executar o comportamento (auto eficácia ou percepção do controle sobre o comportamento). Anteriormente Bird (1988) entendeu a intenção empresarial como o nível de consciência cognitiva direta para criar um novo negócio, explicando que essa intenção é uma situação de pensamento consistente em concentração, experiência e comportamento individual, em direção a objetivo específico ou certo comportamento. Nesse sentido, a decisão de se tornar um empreendedor pode ser considerada de forma plausível como voluntária e consciente (KRUEGER; REILLY; CARSRUD, 2000). Liñán e Fayolle (2015) e Santos, Martins e Silveira (2019) afirmam, ao estudarem sobre a TCP, que essa vem sendo reconhecida, ao longo do tempo, podendo ser considerada como modelo teórico que ampara o tema.

A decisão de agir é fundamentada na experimentação, na perda aceitável, na flexibilidade e nos acordos prévios (CHANDLER et al., 2011), a que se associam comportamentos proativos orientados para a ação (FISHER, 2012). Portanto, independentemente das perspectivas ou abordagens de investigação, o processo de criar uma organização não é uma tarefa imediata, é um objetivo que se concretiza ou vai se concretizando, em médio e longo prazo (ELFVING; BRÄNNBACK; CARSRUD, 2009; KRUEGER, 2009; CHANDLER et al., 2011; CARSRUD; BRÄNNBACK, 2011) e que está condicionado pela interposição de barreiras que, em última análise, impossibilitam a concretização de intenções empreendedoras potencialmente válidas.

Ajzen (2011) afirma, ainda, que, em geral, quanto mais favoráveis forem as atitudes e as normas subjetivas, mais provável é que se estabeleça uma intenção de comportamento. No entanto, a importância relativa de cada um dos componentes varia de comportamento para comportamento, assim como de população para população. É importante notar que a IE está relacionada ao comportamento de duas maneiras distintas: indiretamente, pelo impacto nas intenções, e diretamente, influenciando de forma mais direta o comportamento.

Schaefer et al. (2017) investigaram a existência de relações positivas entre valores pessoais e atitudes na intenção empreendedora de universitários, por meio de questionário aplicado a 204 estudantes de graduação em administração de duas instituições de ensino brasileiras no Rio Grande do Sul; os resultados evidenciaram que os valores pessoais influenciaram positivamente a Atitude $(\mathrm{R}=0,152)$ e que a Atitude impactou fortemente a Intenção Empreendedora $(\mathrm{R}=0,773)$ dos estudantes investigados.

A partir da TCP de Ajzen (1991), que considera os fatores comportamentais e a intenção empreendeora, apresenta-se a seguinte hipótese de pesquisa:

H4: Os fatores comportamentais "atitude", "normas subjetivas" e "percepção e controle do comportamento" distinguem os estudantes com intenção empreendedora.

Cabe ressaltar, neste contexto, que as especificidades nacionais se manifestam no modo como as pessoas apreendem a realidade e a transformam em percepções para um empreendimento. Nesse sentido, é de suma importância discutir a dimensão sociocultural, para a demarcação adequada de distinções em relação ao processo de formação de empresas, investigando-se as razões que conduzem os indivíduos a se tornarem empreendedores, as quais sempre trazem muito da família e, sobretudo, do meio (JULIEN, 2010). 


\section{Metodologia}

Com fins de atender aos requisitos do objetivo proposto, a presente pesquisa tem abordagem quantitativa e descritiva. Segundo Günther (2006), a pesquisa de natureza quantitativa tem características como: controle máximo sobre o experimento; neutralidade e objetividade do pesquisador em relação ao seu objeto de estudo, sem considerar sentimentos e percepções; e avaliação dos dados coletados por uma linguagem matemática, a qual faz uso das análises estatísticas e das teorias de probabilidade para explicar os fenômenos.

Esta pesquisa foi realizada na região Sudoeste do Estado do Paraná. Definiu-se como população deste estudo os estudantes universitários matriculados no $3^{\circ}$ e $4^{\circ}$ anos dos cursos de graduação em administração, na modalidade presencial, das IES estabelecidas nessa região. A seleção da amostra seguiu orientações de estudos anteriores, referenciados por Rueda, Moriano, e Liñán (2015), e que utilizaram como amostra de pesquisa estudantes de gestão de empresas. Pesquisar estudantes universitários se revela como uma tendência em estudos de intenção empreendedora, na literatura, conforme Rueda, Moriano e Liñán (2015).

Segundo dados do e-MEC (BRASIL, 2017), na região Sudoeste do Paraná, estão estabelecidas 19 IES que ofertam o Curso de Administração, na modalidade presencial. Em um primeiro contato, identificou-se que das 19 instituições, quatro haviam encerrado suas atividades. Também, identificou-se que uma instituição estava no seu primeiro ano de funcionamento. E não houve êxito de respostas com outras três instituições. Após nova tentativa via e-mail, também não se obteve êxito. Estas oito instituições foram desconsideradas da pesquisa. Obteve-se êxito no contato com onze instituições, que concordaram em participar da investigação.

$\mathrm{O}$ instrumento de coleta de dados, em forma de questionário estruturado, foi enviado aos coordenadores dos cursos selecionados, via computador ou celular, na modalidade em linha. A amostra foi significativa, de 403 estudantes universitários, correspondendo a mais de $90 \%$ do universo de alunos, das onze instituições pesquisadas. Foram validados 371 respondentes, com questionários respondidos corretamente. O questionário foi composto pelos seguintes itens: (1) Questionário sociodemográfico, incluindo as questões sobre acesso à educação para o empreendedorismo, e (2) Questionário de Intenção Empreendedora (QIE), de Liñán e Chen (2009) e revisto por Liñán, Urbano e Guerrero (2011). As questões foram fechadas e escalares, ancoradas em uma escala do tipo Likert, de cinco pontos, que varia de discordo totalmente (1) até concordo totalmente (5).

No Quadro 1 apresenta-se, primeiro, a variável dependente; em seguida, expõem-se as variáveis independentes da presente pesquisa.

Quadro 1 - Variáveis da pesquisa

\begin{tabular}{|l|l|}
\hline \multicolumn{2}{|c|}{ VARIÁVEL DEPENDENTE } \\
\hline \multicolumn{2}{|c|}{ Intenção empreendedora } \\
\hline \multicolumn{2}{|c|}{ VARIÁVEIS INDEPENDENTES } \\
\hline \multicolumn{1}{|c|}{ Sociodemográficas } & \multicolumn{1}{c|}{ Comportamentais } \\
\hline Renda familiar & Atitude \\
\hline Cursou disciplina de empreendedorismo durante a graduação & Normas subjetivas \\
\hline $\begin{array}{l}\text { Teve acesso a programa de educação para o empreendedorismo } \\
\text { extraclasse oferecido pela instituição }\end{array}$ & $\begin{array}{l}\text { Percepção Controle do } \\
\text { Comportamento }\end{array}$ \\
\hline Possui parentes de primeiro grau empreendedores & \\
\hline
\end{tabular}




\begin{tabular}{|l|l|}
\hline Atividade profissional atual & \\
\hline Gênero & \\
\hline
\end{tabular}

Fonte: os autores.

Os resultados demonstram que a confiabilidade (Alfa de Cronbach) foi satisfatória em todos os constructos, pelo que se considera que a consistência interna é adequada. Isso decorre pelo fato de esta superar o valor recomendado de 0,70, abaixo do qual a consistência interna da escala utilizada é considerada baixa. O valor máximo esperado é 0,90 , usualmente, são preferidos valores de alfa entre 0,80 e 0,90 (STREINER, 2003).

Utilizou-se como método multivariado a regressão logística. Para Hair Junior et al. (2009), a regressão logística tem como principal objetivo determinar a probabilidade de um determinado evento ocorrer, tendo em conta a variável dependente em função das variáveis independentes. Na regressão logística, a variável de saída é categórica dicotômica, e as variáveis previsoras são contínuas ou categórica (FIELD, 2009).

De acordo com Gujarati (2000), nesses modelos, a variável dicotômica é uma variável "dummy", que assume os valores 0 ou 1, o que, na análise em questão, representa: 0 - Alunos com intenção de empreender, sendo estes 206 alunos, e 1 - Alunos sem intenção de empreender, sendo estes 165 alunos, totalizando os 371 respondentes.

\section{Análises e discussões dos resultados da pesquisa}

Com os dados obtidos, desenvolveu-se a construção dos modelos de regressão logística, utilizando-se o software estatístico Statistical Package for the Social Sciences (SPSS). Na regressão logística a probabilidade pode ser determinada por vários fatores (variáveis explicativas), representados por Xi $\beta$, regredidos sobre a variável dependente (Y) (FAVERO, 2009). Dentre esses fatores têm-se as variáveis sociodemográficas e o grupo das variáveis comportamentais.

Na regressão logística, o modelo pode ser definido conforme a Equação 1:

$$
\text { in }(\text { chance })=\alpha+\beta 1+X 1+\beta 2+X 2 \ldots \beta 13+X 13
$$

Apresenta-se, na sequência, o modelo inicial com todos os constructos para posteriormente formar o modelo final com resultados mais adequados e maior força de predição. A simulação escolhida inicialmente utilizou como variáveis independentes, sendo 13 os constructos referentes: Fatores sociodemográficos: renda familiar, cursou disciplina de empreendedorismo, participou de programas de educação para o empreendedorismo, possui parentes de primeiro grau empreendedores, atividade profissional atual, gênero; Fatores comportamentais: atitude, normas subjetivas, percepção e controle.

Neste trabalho, inicialmente, todas as variáveis foram incluídas para construção do modelo. Entretanto, no modelo logístico final, apenas algumas variáveis foram selecionadas, uma vez que se buscam critérios que otimizem o modelo, reduzindo a variância e evitando problemas de multicolinearidade.

No que se refere à avaliação da qualidade do ajustamento, há dois testes de significância do modelo final, segundo Favero (2009): o teste Qui-Quadrado da mudança no valor de -2LL (Teste Omnibus) e o teste de Hosmer e Lemeshow. Esses testes possibilitam analisar, após a inclusão das variáveis independentes, se o modelo pode ser considerado capaz de realizar as predições com a acurácia desejada (FAVERO, 2009). No que se refere à avaliação da qualidade 
do ajustamento, o modelo da Tabela 1 apresenta os valores das quatro medidas: - $2 \log$ likelihood, Cox \& Snell, Nagelkerke e Teste de Hosmer \& Lemeshow. O valor da medida - 2 log likelihood, com valor de 408,234, segundo Favero (2009), não possui normalmente uma interpretação direta, porém interfere no resultado do teste. Quanto aos coeficientes de determinação de Cox \& Snell e de Nagelkerke, são semelhantes ao $\mathrm{R}^{2}$ da Regressão Linear (FAVERO, 2009), e indicam, respectivamente, que as variáveis independentes selecionadas do modelo logístico estimado explicam $19,9 \%$ e $27,2 \%$ da variância da variável dependente, o que pode ser considerado um valor razoável da qualidade de ajustamento. O valor de Hosmer \& Lemeshow apresentou uma distribuição Qui-Quadrado de 8,313 e um nível de significância de 0,403, o que indica que não há diferenças significativas entre as frequências previstas e as observadas. O percentual global do modelo é de $71,7 \%$, por meio do resultado do Overall Percentage, assim, o percentual de acerto dos alunos que não têm intenção empreendedora é de $54 \%(=75 /(75+64))$, e o dos que estão dispostos a empreender seria de $82,3 \%(=41 /(41+$ 191)). O modelo logístico apresenta um acerto global de 71,7\% $(=(75+41) /(75+41+64+$ 191)), o que atesta uma excelente capacidade de previsão do modelo.

Tabela 1 - Ajuste do Modelo

\begin{tabular}{|c|c|c|c|c|c|}
\hline $\begin{array}{c}-2 \text { Log } \\
\text { Likelihood }\end{array}$ & $\begin{array}{c}\text { Crox \& Snell } \\
R^{2}\end{array}$ & $\begin{array}{c}\text { Nagelkerk } e \\
R^{2}\end{array}$ & $\begin{array}{c}\text { Teste de Hosmer } \\
\text { Lemeshow } \\
\text { Qui-quadrado df }\end{array}$ & $\&$ & $\begin{array}{c}\text { Overall } \\
\text { Percentage }\end{array}$ \\
\hline $408,234^{a}$ & , 199 & 272 & $8,313 \quad 8 \quad, 403$ & & 1,7 \\
\hline
\end{tabular}

Fonte: os autores.

A Tabela 2 apresenta os resultados dos parâmetros estimados e os constructos que se mostraram significativos no modelo, a partir da estatística de Wald, e, também os que não foram, a um nível de significância (Sig.) de 5\%.

Tabela 2 - Nível de significância - Modelo inicial

\begin{tabular}{|c|c|c|c|c|c|}
\hline Variável & $\begin{array}{l}\text { Coeficiente } \\
\text { B }\end{array}$ & $\begin{array}{l}\text { Erro } \\
\text { S.E. }\end{array}$ & $\begin{array}{l}\text { Estatística } \\
\text { Wald }\end{array}$ & $\begin{array}{l}\text { Nível de } \\
\text { Significância }\end{array}$ & $\begin{array}{l}\text { Oldds Ration } \\
\text { Exp(B) }\end{array}$ \\
\hline Renda familiar & ,108 & , 102 & 1,131 & ,288 & 1,114 \\
\hline $\begin{array}{l}\text { Cursou disciplina de } \\
\text { empreendedorismo }\end{array}$ & ,086 & ,270 &, 101 & ,751 & 1,090 \\
\hline Acesso a programas de EE & ,395 & 251 & 3,144 & ,005 & 1,500 \\
\hline $\begin{array}{l}\text { Possui parentes primeiro grau } \\
\text { empreendedores }\end{array}$ &,- 323 & ,262 & 1,523 & ,217 &, 724 \\
\hline Atividade profissional atual & ,188 & ,074 & 6,548 & ,011 & 1,207 \\
\hline Gênero & 213 & 254 &, 701 & 402 & 1,237 \\
\hline Atitude &, 588 &, 110 & 28,841 & ,000 & 1,801 \\
\hline Constant & $-6,192$ & 1,302 & 22,630 & 000 &, 002 \\
\hline
\end{tabular}

Fonte: os autores.

Constata-se, no modelo inicial, a existência de quatro variáveis explicativas que não são estatisticamente significativas (Sig.) com um resultado superior a 5\%: "Renda familiar", "Cursou disciplina de empreendedorismo", "Possui parentes de primeiro grau empreendedores" e "Gênero". Os resultados mostram que essas variáveis explicativas não têm significância estatística nesse modelo; por isso, nada se pode concluir relativamente ao efeito dessas variáveis na intenção empreendedora. Perante esses resultados, não é possível confirmar empiricamente as hipóteses $\mathrm{H} 1$ e $\mathrm{H} 2$. 
Hipótese H1: O fator sociodemográfico família distingue os estudantes com intenção empreendedora, foi rejeitada. Esse resultado difere de outras pesquisas. Na de Medina, Bolívar e Lemes (2014) o fato de "ter alguém empreendedor na família" se mostra positivo e motiva os jovens a se envolverem no empreendedorismo. O mesmo ocorreu na pesquisa de Olmos e Castilho (2015), que mostra forte influência da experiência empreendedora da família na intenção de criação de negócios.

Hipótese H2: O fator sociodemográfico Gênero distingue os indivíduos com intenção empreendedora, foi rejeitada. Ao se observarem os resultados de pesquisa anteriores, buscando contextualizar a rejeição da $\mathrm{H} 2$, nota-se que esse resultado difere das pesquisas de Ventura e Quero (2013) e de Soria-Barreto et al. (2017). As duas pesquisas evidenciaram, em seus estudos, que há influência de gênero na IE dos indivíduos pesquisados. Entretanto, a rejeição da H2 se assemelha com a pesquisa de Tarapuez, García e Castellano (2018), na qual os resultados mostraram que o gênero não influencia na intenção de negócios dos estudantes universitários.

A Tabela 3 demonstra o modelo final, retirando os constructos que não se fizeram significativos no modelo inicial. Nesse modelo as variáveis explicativas apresentaram significância (Sig.) inferior a 0,1\%. Pode-se concluir com um nível de confiança de 99,9\%, que na amostra dos alunos pesquisados, existe uma relação entre essas variáveis e a probabilidade de o aluno ter ou não intenção empreendedora.

Tabela 3 - Nível de significância - Modelo final

\begin{tabular}{lrrrrrr}
\hline \multicolumn{1}{c}{ Variável } & $\begin{array}{c}\text { Coeficiente } \\
\text { B }\end{array}$ & \multicolumn{1}{c}{$\begin{array}{c}\text { Erro } \\
\text { S.E. }\end{array}$} & $\begin{array}{c}\text { Estatística } \\
\text { Wald }\end{array}$ & $\begin{array}{c}\text { Nível de } \\
\text { Significância }\end{array}$ & $\begin{array}{c}\text { Oldds Ration } \\
\text { Exp(B) }\end{array}$ \\
\hline Acesso à programas de EE & $\mathbf{3 0 0}$ &, 147 & 4,165 & $\mathbf{, 0 0 8}$ & 1,305 \\
Atividade profissional atual & $\mathbf{, 2 2 5}$ &, 070 & 10,437 & $\mathbf{, 0 0 1}$ & 1,252 \\
Atitude & $\mathbf{, 5 8 7}$ &, 109 & 29,083 & $\mathbf{, 0 0 0}$ & 1,798 \\
Normas Subjetivas & $\mathbf{, 3 5 3}$ &, 149 & 5,619 & $\mathbf{, 0 1 0}$ & 1,423 \\
Percepção Controle & $\mathbf{, 6 1 6}$ &, 177 & 12,135 & $\mathbf{, 0 0 0}$ & 1,851 \\
Constant & $-6,037$ & 1,073 & 31,633 &, 000 &, 002 \\
\hline
\end{tabular}

Fonte: os autores.

Destaca-se, também, entre os resultados da regressão logística, o valor do odds ratio, que é calculado para cada variável explicativa do modelo logístico, o que demonstra a variação à medida que o valor da variável explicativa é acrescido em uma unidade. Assim, destaca-se uma variação positiva de uma unidade nas variáveis "Percepção e Controle", "Atitude", "Normas Subjetivas", "Acesso à programas de EE" e "Atividade profissional atual". Em ordem crescente de variáveis se verifica elevado impacto positivo na probabilidade de um aluno ter intenção empreendedora, ou seja, quanto maior o valor dessa variáveis, maior é a probabilidade de o aluno ter intenção empreendedora.

Com base na Tabela 3, visualiza-se o Coeficiente B, que demonstra os efeitos exatos de diferentes valores de variáveis no modelo final e podem ser calculados na seguinte equação:

Intenções empreendedoras $=-6,037+, 300$ (Acesso à programas de $\mathrm{EE})+, 225$ (Atividade profissional atual),+ 587 (Atitudes),+ 353 (Normas Subjetivas),+ 616 (Percepção Controle) 
Em resumo, todos os constructos do modelo final demonstram um impacto positivo nas intenções empreendedoras. O modelo final, o valor de Nagelkerk correspondente ao $\mathrm{R}^{2}$, teve um pequeno aumento, explicando $28,2 \%$ da variação nas intenções empresariais, fortalecendo a capacidade de explicação do modelo.

Constata-se que tanto no modelo inicial, quando no modelo final, as hipóteses $\mathrm{H} 3$ e $\mathrm{H} 4$ foram aceitas.

Hipótese H3: $O$ fato de ter tido acesso à programas de educação para o empreendedorismo dentro da universidade distingue os estudantes com intenção empreendedora. Esse resultado se assemelha ao pesquisado por Ferreira, Fernandes e Ratten (2016) e reforça o papel positivo da educação para o empreendedorismo na intenção empreendedora. A partir desses resultados, reforça-se a importância da educação para o empreendedorismo dentro das universidades, e evidenciando também semelhanças com os resultados de Schaefer e Minello (2019). Esses dois autores brasileiros concluíram que o processo de aprendizagem na educação empreendedora, por meio de aprendizagem formal, experimental e indireta, desenvolvem comportamentos e características de mentalidade voltados para o empreendedorismo, em estudantes e professores. Dentre outros, destacam-se especialmente duas pesquisas que comprovaram a existência de uma relação positiva entre a educação empreendedora e a intenção empreendedora: a de Bae et al. (2014) e a de Krüger, Bürger; e Minello (2019).

Hipótese H4: Os fatores comportamentais "atitude", "normas subjetivas" e "percepção e controle do comportamento" distinguem os estudantes com intenção empreendedora. De forma geral, observando os resultados dos fatores comportamentais, esses se fortalecem com base nas teorias que abordam que os fatores individuais ajudam a explicar a intenção de empreender (KRUEGER; REILLY; CARSRUD, 2000; OLMOS; CASTILHO, 2015; SCHAEFER et al., 2017; JOSEPH, 2017; NGUYEN, 2017). Esses resultados se assemelham ainda aos achados de Nguyen (2017), que investigou a intenção empresarial entre os estudantes de negócios internacionais no Vietnã. Os resultados confirmaram que a atitude em relação ao empreendedorismo e ao controle do comportamento percebido está positivamente relacionada à intenção empresarial, com uma variância de 30,7\%. Porém, diferente da presente pesquisa, as Normas Subjetivas não geraram um impacto significativo na IE. Também na pesquisa de Schaefer et al. (2017), os resultados evidenciaram que os valores pessoais influenciaram positivamente a Atitude $(\mathrm{R}=0,152)$ e que a Atitude impactou fortemente na Intenção Empreendedora $(\mathrm{R}=0,773)$ dos estudantes investigados. Novamente ao comparar os resultados da presente pesquisa com os achados no Brasil, na pesquisa de Souza, Silveira e Nascimento (2018) esses resultados se apoiam, no sentido de demonstraram relações positivas e significativas, explicando 57,3\% da variância da IE. A relação entre atitude e intenção demonstrou a maior força dentre as relações observadas.

Observando os resultados da presente pesquisa, na qual os fatores comportamentais apresentaram o maior poder de explicação, reafirma-se, com isso, a teoria de Ajzen (2001), que demonstra que as Atitudes e o constructo Percepção e Controle são os melhores preditores das intenções para o empreendedorismo.

\section{Conclusões}


O empreendedorismo apresenta aspectos sociodemográficos e comportamentais, entre outros, todos inter-relacionados e complementares, o que contribui para a afirmação de que o processo empreendedor não pode ser visto de maneira unidimensional. Assim, a compreensão da natureza empreendedora e de como pensa e age o indivíduo empreendedor pode nortear as ações a serem realizadas com o propósito de criar sujeitos, organizações e ambientes empreendedores que gerem desenvolvimento humano, competitividade e crescimento econômico e social.

Os resultados da regressão logística binária indicam que as variáveis no modelo influenciam as intenções empresariais. Sendo que os fatores comportamentais são os que possuem maior poder de explicação nas intenções empreendedoras dos estudantes, da mesma forma que as constatações de outros estudos, a percepção e controle comportamental e a atitude estão positivamente relacionados às intenções empreendedoras. Seguido dos fatores acesso à educação para o empreendedorismo e atividade profissional atual. Na presente pesquisa gênero, familiar empreendedor e renda não se mostraram significativos no modelo.

Ao concluir a pesquisa cabe destacar a evidência da educação empreendedora, que se apresenta como um apoio à formação de melhores empreendedores, uma vez que proporciona habilidades e aperfeiçoamento de competências, além de possibilitar cenários de oportunidades de negócios.

Os resultados podem servir para que se faça uma reflexão sobre a possibilidade de investigar a temática da intenção empreendedora de forma mais permanente e sistemática, nos programas de graduação em Administração, no país, servindo de apoio e oportunizando avaliação sobre empreender ou não empreender, em função de determinados conhecimentos adquiridos. Evidentemente se recomendam estudos posteriores. Sendo a temática do empreendedorismo ainda recente, em desenvolvimento e de interesse, advoga-se que o aumento do conhecimento sobre empreender ou não empreender, e seus fatores condicionantes, como forma de amparar novas compreensões e perspectivas. Essas incentivam naturais superação de possíveis limitações.

\section{Referências}

AJZEN, I. Behavioral Interventions: Design and Evaluation Guided by the Theory of Planned Behavior. In: MARK, M. M.; DONALDSON, S. I.; CAMPBEL, B. (ed.). Social Psychology and Evaluation. New York: Guilford Press, 2011. p. 72-100.

\section{The Theory of Planned Behavior. Organizational and Human Decision}

Processes, v. 50, n. 12, p. 179-211, 1991.

BAE, T. J. et al. The relationship between entrepreneurship education and entrepreneurial intentions: a meta-analytic review. Entrepreneurship: Theory and Practice, v. 38, n. 2, p. 217-254, 2014.

BIGNOTTI, A.; LE ROUX, I. Unravelling the conundrum of entrepreneurial intentions, entrepreneurship education, and entrepreneurial characteristics. Acta

Commer, Johannesburg, v. 16, n. 1, p. 1-10, 2016. 
BIRD, B. Implementing entrepreneurial ideas: The case for intention. Academy of Management Review, v. 13, n. 3, p. 442-453, 1988.

BRASIL. e-MEC: Instituições de Educação Superior e Cursos Cadastrados. 2017. Disponível em: http://emec.mec.gov.br. Acesso em: 10 abr. 2017.

CARSRUD, A.; BRÄNNBACK, M. Entrepreneurial motivations: what do we still need to know? Journal of Small Business Management, v. 49, n. 1, p. 9-26, 2011.

CHANDLER, G. N. et al. Causation and effectuation processes: a validation study. Journal of Business Venturing, v. 26, n. 3, p. 375-390, 2011.

DOS SANTOS, E. I.; SÁ BARRETO, R. C.; GUZMAN, S. J. M. Modelo estrutural para os fatores determinantes da oferta de empreendedores criativos: Ilhéus e Itabuna. Revista de Empreendedorismo e Gestão de Pequenas Empresas, v. 6, n. 1, p. 160-195, jan./abr. 2017.

ELFVING, J.; BRÄNNBACK, M.; CARSRUD, A. Toward a contextual model of entrepreneurial intentions. In: CARSRUD, A.; BRÄNNBACK, M. (ed.). Understanding the Entrepreneurial Mind: Opening the Black Box. New York: Springer, 2009. p. 23-33.

FAVERO, L. P. Análise de dados: modelagem multivariada para tomada de decisões. Rio de Janeiro: Elsevier, 2009.

FAYOLLE, A. Personal views on the future of entrepreneurship education,

Entrepreneurship \& Regional Development, v. 25, n. 7-8, p. 692-701, 2013.

.; LIÑÁN, F. The future of research on entrepreneurial intentions. Journal of

Business Research, v. 67, n. 5, p. 663-666, 2014.

FERREIRA, J.; FERNANDES, C.; RATTEN, V. The Influence of Entrepreneurship Education on Entrepreneurial Intentions, Entrepreneurial Universities, v. 1, n. 1, p. 19-34, 2016.

FIELD, A. Discovering Statistics Using SPSS. 3. ed. London: Sage Publications Ltd., 2009.

FISHER, G. Effectuation, causation, and bricolage: A behavioral comparison of emerging theories in entrepreneurship research. Entrepreneurship theory and practice, v. 36, n. 5, p. 1019-1051, 2012.

FRANCO, J. O. B.; GOUVÊA, J. B. A cronologia dos estudos sobre o empreendedorismo. In: FRITSCH, M. How is New Business Training affect regional development? Introduction to Emission. Small Business Economics, v. 30, n. 1, p. 1-14, 2008.

GUJARATI, D. N. Econometria básica. São Paulo: Makron Books, Pearson Education do Brasil, 2000. 
GÜNTHER, H. Pesquisa Qualitativa Versus Pesquisa Quantitativa: Esta É a Questão?

Psicologia: Teoria e Pesquisa, v. 22 n. 2, p. 201-210, 2006.

HAIR JUNIOR, J. F. et al. Análise multivariada de dados. 6. ed. Porto Alegre: Bookman, 2009.

JOSEPH, I. Factors influencing international student entrepreneurial intention in Malaysia.

American Journal of Industrial and Business Management, v. 7, p. 424-428, 2017. DOI: 10.4236/ajibm.2017.74030

JULIEN, P.-A. Empreendedorismo regional e a economia do conhecimento. São Paulo: Saraiva, 2010.

KRÜGER, C.; BÜRGER, R. E.; MINELLO, I. F. O Papel Moderador da Educação Empreendedora Diante da Intenção Empreendedora. Revista Economia \& Gestão, v. 19, n. 52, p. 61-81, 2019.

KRUEGER, N. F. Entrepreneurial Intentions are dead: Long live entrepreneurial intentions. In: CARSRUD, A.; BRÄNNBACK, M. (ed.). Understanding the Entrepreneurial Mind: Opening the Black Box. New York: Springer, 2009. p. 51-72.

.; REILLY, M. D.; CARSRUD, A. L. Competing models of entrepreneurial intentions. Journal of Business Venturing, v. 15, n. 5, p. 411-432, 2000.

LANDSTRÖM, H.; HARIRCHI, G.; ASTRÖM, F. Entrepreneurship: Exploring the Knowledge base. Research Policy, v. 41, n. 7. p. 1154-1181, set. 2012.

LIMA, E. et al. Opportunities to Improve Entrepreneurship Education: Contributions Considering Brazilian Challenges. Journal of Small Business Management, v. 53, p. 10331051, 2015a.

. et al. Ser seu próprio patrão? Aperfeiçoando-se a Educação Superior em empreendedorismo. Revista de Administração Contemporânea, v. 19, n. 4, p. 419-439, 2015 b.

LIÑÁN, F. Skill and value perceptions: how do they affect entrepreneurial intentions? International Entrepreneurship and Management Journal, v. 4, n. 3, p. 257-272, 2008.

.; CHEN, Y. W. Development and Cross-Cultural Application of a Specific Instrument to Mensure Entrepreneurial Intentions. Entrepreneurship Theory and Practice, Baylor University, May 2009.

.; FAYOLLE, A. A systematic literature review on entrepreneurial intentions: citation, thematic analyses, and research agenda. International Entrepreneurship and Management Journal, v. 11, n. 4, p. 907-933, 2015. 
.; RODRIGUEZ-COHARD, J. C.; RUEDA-CANTUCHE, J. M. Factors affecting entrepreneurial intention levels: a role for education. International Entrepreneurship and Management Journal, v. 7, n. 2, p. 195-218, 2011.

.; URBANO, D; GUERRERO, M. Regional variations in entrepreneurial cognitions: start-up intentions of university students in Spain. Entrepreneurship \& Regional Development, v. 23, n. 3-4, p. 187-215, Apr. 2011.

LOPES, R. M. A. Referenciais para a educação empreendedora. In: LOPES, R. M. A. (org.). Educação empreendedora: conceitos, modelos e práticas. Rio de Janeiro: Elsevier, 2010. p. $17-44$.

MARTINS, F. S.; SANTOS, E.B.A.; SILVEIRA, A. Entrepreneurial intention: Categorization, classification of constructs and proposition of a model. BBR - Brazilian Business Review, v. 16, n.1, 46-62, 2019.

MEDINA, P.; BOLIVAR, A.; LEMES, A. Un paso mas en la investigacion de la intencion empreendedora del estudiante universitario Guesss. Revista de Estudios Empresariales, v. 2, n. 1, p. 63-80, 2014.

NECK, H. M. et al. Teaching entrepreneurship: a practice-based approach. Cheltenham: Edward Elgar, 2014.

NGUYEN, C. Entrepreneurial intention of international business students in Viet Nam: a survey of the country joining the Trans-Pacific Partnership. Journal of Innovation and Entrepreneurship, v. 6, n. 7, p. 1-13. 2017.

OLIVEIRA, D. G. A evolução conceitual da educação para o empreendedorismo como um campo científico. Revista Alcance, v. 23, n. 4, p. 547-567, 2016.

OLMOS, R. E.; CASTILHO, A. S. Personality traits versus work values: Comparing psychological theories on entrepreneurial intention. Journal of Businnes Research, v. 68, n. 7, p. 1595-1598, 2015.

PAIVA, L. E. B. et al. Sustainability, Innovation, and Entrepreneurship: A Research with Administration and Secretariat Students. Revista de Negócios, v. 24, n. 3, p. 7-26, 2019

RUEDA, S.; MORIANO, J. A.; LIÑÁN, F. Validating a theory of planned behavior questionnaire to measure entrepreneurial intentions. In: FAYOLLE, A.; KYRÖ, P.; LIÑÁN, F. (ed.). Developing, Shaping and Growing Entrepreneurship. Cheltenham: Edward Elgar, 2015. p. 60-78. 
SÁNCHEZ, J. C. Aprendizaje social e intenciones emprendedoras: Un estudio comparativo entre México, España y Portugal. Revista Latinoamericana de Psicología, v. 41, n. 1, p. 109-119, 2009.

SCHAEFER, R. et al. Valores pessoais, atitudes e intenção empreendedora: um estudo com estudantes de graduação em administração. Revista Economia \& Gestão, v. 17, n. 47, p. 123-143, 2017.

.; MINELLO, I. F. Entrepreneurial Education: Entrepreneurial Mindset and Behavior in Undergraduate Students and Professors. Revista de Negócios, v. 24, n. 2, p. 6190, 2019.

SHANE, S. Why Encouraging More People to Become Entrepreneurs Is Bad Public Policy. Small Business Economics, v. 33, n. 2, p. 141-149, 2009.

SILVA, J. F.; PENA, R. P. M. O "bê-á-bá” do ensino em empreendedorismo: uma revisão da literatura sobre os métodos e práticas da educação empreendedora. Revista de

Empreendedorismo e Gestão de Pequenas Empresas, v. 6, n. 2, p. 372-401, 2017.

SILVEIRA, A. et al. Factors and Approaches of Entrepreneurial Intention. Revista de Empreendedorismo e Gestão de Pequenas Empresas, v. 6, n. 2, p. 263-290, 2017.

SORIA-BARRETO, K. et al. Prior Exposure and Educational Environment towards Entrepreneurial Intention. Journal of Technology Management \& Innovation, Santiago, v. 12, n. 2, p. 45-58, 2017.

SOUZA, R. dos S.; SILVEIRA, A.; NASCIMENTO, S. do. Ampliando a mensuração da intenção empreendedora. Revista de Administração FACES Journal, v. 17, n. 2, p. 74-93, abr./jun. 2018.

STREINER, D. L. Being inconsistent about consistency: when coefficient alpha does and doesn’t matter. Journal of Personality Assessment, v. 80, p. 217-222, 2003.

TARAPUEZ, E.; GARCÍA, M. D.; CASTELLANO, N. Aspectos socioeconómicos e intención emprendedora en estudiantes universitarios del Quindío (Colombia). Innovar, v. 28 , n. 67, p. 123-135, 2018.

TORRES, F. et al. Exploring entrepreneurial intentions in Latin American university students Explorando las intenciones emprendedoras en estudiantes universitarios Latinoamericanos. International Journal of Psychological Research, v. 10, n. 2, p. 46-59, 2017.

VENTURA, R.; QUERO, M. Factores explicativos de la intención de emprender en la mujer. Aspectos diferenciales en la población universitaria según la variable género. Cuadernos de Gestión, v. 13, n. 1, p. 127-149, 2013. 
VIANA, G. et al. O capital social e o empreendedorismo: notas de leituras. Revista Capital Científico, v. 14, n. 2, 2016. 